\title{
Research on Evaluation of Morality and Ability of Teachers in Universities Based on the Perspective of Data Mining
}

\author{
Li Tang \\ Department of Information Science and Technology \\ Tianjin University of Finance and Economics \\ Tianjin, China \\ tangli0831@tjufe.edu.cn
}

Li He

Department of Information Science and Technology

Tianjin University of Finance and Economics

Tianjin, China

renkeheli@163.com

\author{
Caiyun Zhou \\ Department of Economics \\ Tianjin University of Finance and Economics \\ Tianjin, China \\ zhoucaiyun_0119@163.com
}

\author{
Shuhua Zhang \\ Coordinated Innovation Center for Computable Modeling in \\ Management Science \\ Tianjin University of Finance and Economics \\ Tianjin, China \\ shuhua55@126.com
}

\begin{abstract}
The evaluation of professional morality and ability of teachers is an important part of management in the colleges and universities. Focusing on the evaluation of teachers in Chinese universities, this paper designs an evaluation model, and constructs an evaluation metrics from the perspective of data mining. Furthermore, a new evaluation method for teachers based on Support Vector Machine (SVM) is proposed. The prediction levels of the morality and ability of teachers will be given by SVM. Finally, it gives the relative policies to promote the morality and ability of teachers. It will efficiently improve the quality of teaching and bring benefit to the teaching reform.
\end{abstract}

Keywords-Support Vector Machine (SVM); Morality of Teachers; Ability of teachers; Data Mining

\section{INTRODUCTION}

The morality of teachers is the abbreviation of the professional morality of teachers, and it includes the moral consciousness, moral relations and moral activity of teachers. The ability of teachers in colleges and universities includes teaching ability, scientific research ability, practical ability, management ability and so on. A good morality of teachers is a prerequisite for teaching, while a good professional ability of teachers is a powerful guarantee to improve the quality of education.

It is very important to strengthen the management of teaching and improve the quality of education in the colleges and universities. It is also urgent to improve the professional morality and professional ability of teachers. With the rapid development of information technology, the new era and the current form of education put forward higher requirements for the ability of modern teachers. The traditional ability of teachers cannot adapt to the social development and meet the needs of education.

At present, there are three major problems in our college teaching.

Firstly, some teachers do not act well in the teaching. For example, the inquiry ability and innovation ability of some teachers is insufficient. They read professional books without thorough understanding, and are lack of ability of innovation. The professional ability and practical ability of some teachers need to be improved. There are some teachers tend to seek fame and wealth. Because of the interests of money, they do not pay attention to teaching, and turned to higher economic benefits of short-term projects.

Secondly, according to the policy of education expansion, the directors in charge of education department are mostly focused on the construction and investment of hardware. They pay too much attention to hardware investment and evaluation of scientific research, and do not attach importance to the quality of education and teaching reform.

Thirdly, there are some problems in the current policies and mechanisms. The evaluation and incentive mechanism of teachers are only based on the achievement of scientific research. The promotion of professional ranks is in the light of papers and foundations. These mechanisms lead to the atmosphere of emphasizing the scientific research and ignoring the teaching in the universities.

In a word, it is important to improve the morality and ability of teachers. It is urgent to realize the reform of education. Because the morality and ability of teachers are often difficult to quantify, there are some deficiencies in the current evaluation system and mechanism in China.

This research is supported by the Tianjin Social Science Foundation of China (TJYY15-017) 
The contents of teaching evaluation include the moral consciousness of teachers, their professional ability, the level of scientific research, teaching design, teaching methods, teaching skills, the effect of teaching, and so on. Therefore, it is necessary to make use of the advantages of big data and information technology, and apply them to the teaching reform and evaluation. Take advantage of advanced information technology to establish the unified and reasonable evaluation model and strengthen the evaluation mechanism of performance. It will provide an important basis for the measurement of the morality and ability of teachers.

The purpose of this paper is to realize the teaching reform and the evaluation of the morality and ability of teachers in Chinese universities based on data mining technology. Through the use of data mining technology, it will achieve the evaluation and analysis of the professional morality and ability of teachers, which reflects the scientific and advanced nature of this research. According to the analysis, it will put forward the relevant strategies and suggestions to meet the new requirements of teachers and students in the information age. At the same time, we should fully mobilize the enthusiasm of teachers, cultivate the innovative ability of teachers and improve the ability of teachers. It will lay the foundation for the improvement of the overall teaching level.

\section{RELATED WORKS}

Focusing on the evaluation of the morality and ability of teachers in the universities, scholars have made a lot of research from various views, including the construction of morality and ability of teachers, and some evaluation methods.

Firstly, some research focuses on the morality construction of teachers in the universities. Jiang ming-si demonstrates that the perfection of the morality system of teachers should emphasize the professional morality values, and perfect the morality standard of teachers [1]. It is necessary to pay more attention to training, supervision and evaluation system. Dong kun puts forward the counter measures to solve the problems of strengthening the morality construction of teachers in the universities, which has important practical significance for improving the quality of higher education [2].

Secondly, about the evaluation method of the ability of teachers, the researchers adopt a variety of methods to achieve the evaluation of teachers, including SVM, rough set, group decision-making, association rules and fuzzy method. Zhang J. proposes to simplify the index of evaluation through the neighborhood rough set attribute reduction and combine the Particle Swarm Optimization (PSO) algorithm with SVM [3]. Gao T. builds the evaluation model of research ability of teachers in the universities based on rough set and group Eigen value method [4]. Li L. applies the attribute reduction fast algorithm based on greedy strategy to reducing the research ability attribute of the teachers, and mines the potential rules between the research index and research ability of teachers through the association rule algorithm [5]. However, the association rules algorithm may results in large computation and high space-time complexity when generating association rules. In the evaluation of scientific research, there are a great variety of indicators to be evaluated. Zhang Y. puts forward an evaluation model of teaching ability of teachers in the universities based on the fuzzy comprehensive evaluation, and proposes the evaluation model of the specific composition and the corresponding algorithm [6].

\section{EVALUATION OF THE MORALITY AND ABILITY OF TEACHERS FROM THE PERSPECTIVE OF DATA MINING}

The evaluation of the morality and ability of teachers will take the teaching reform and innovation of thinking as guide, the technology of data mining as method, the cultivation of the ability of teachers as the basis, and the improvement of the quality of teaching as the aim. The contents of the teaching reform include two aspects.

Firstly, by the method of survey, we investigate the teaching situation and collect the relevant data and information in the colleges and universities. To carry out the survey of teachers, we investigate the related situation of the morality and ability of teachers in depth. To carry out a questionnaire survey of students, we inquire into the learning needs of students, and the evaluation of the teaching and the morality of the teachers. The quality and level of teaching is graded by the experts and the other teachers after class.

Through the questionnaire survey and various researches, we collect and sort out the relevant evaluation data of teaching, and build the evaluation index system for the morality and ability of teachers. The evaluation data include: the relevant survey data of the teachers themselves, the evaluation score of the teaching by the students, the scores of the teaching by the experts and the other teachers after class. Its contents are shown in table 1 .

TABLE I. EVALUATION METRICS OF TEACHING

\begin{tabular}{|c|c|}
\hline $\begin{array}{c}\text { The objective of } \\
\text { evaluation }\end{array}$ & The evaluation metrics \\
\hline \multirow{4}{*}{$\begin{array}{l}\text { Teachers } \\
\text { themselves }\end{array}$} & Title \\
\hline & The workload of teaching \\
\hline & The effectiveness of teaching \\
\hline & The achievements of teaching \\
\hline Students & Give a score to the teaching \\
\hline Experts & Grade the teaching \\
\hline $\begin{array}{l}\text { The other } \\
\text { teachers }\end{array}$ & Grade the teaching \\
\hline
\end{tabular}

Secondly, we formulate the evaluation model for the morality and ability of teachers and use the method of data mining to achieve the relevant evaluation. At first, we establish the evaluation model and evaluation mechanism, and make the different evaluation criteria and models for different kinds and different levels of teachers. Furthermore, we utilize the algorithms of data mining and combine with the evaluation model to realize the analysis and evaluation for the morality and ability of teachers, and build a three-dimensional teaching evaluation system.

In order to make a better evaluation, an evaluation model $\mathrm{M}$ is established: 


$$
M=\langle D, F, W, A, P>
$$

$\mathrm{D}$ denotes the data sets of teachers; $\mathrm{F}$ denotes the features of the morality and ability of teachers; $\mathrm{W}$ represents the weight values corresponding to the features, its default value is 1 ; a represents the adopted data mining algorithm, namely SVM algorithm; $\mathrm{P}$ denotes the performance parameters of the algorithm, including precise and recall.

The algorithm of data mining adopted in this paper is Support Vector Machine (SVM) proposed by Vapnik [7]. SVM algorithm is a kind of supervised machine learning method and widely used in statistical classification. It has a greater advantage in the solution of finite sample and nonlinear problems, and also has a stronger generalization ability and better robustness. SVM algorithm will obtain the optimal solution without the problem of dimensionality curse. This paper proposes the evaluation method based on SVM.

The SVM algorithm used in this paper is derived from the LIBSVM software package developed by Lin C. et al. [8]. In the SVM algorithm, there are two steps, including training and prediction. In the training step of SVM, we adopt the RBF kernel function, polynomial kernel function and linear kernel function, respectively. As for the other parameters, we use the default values.

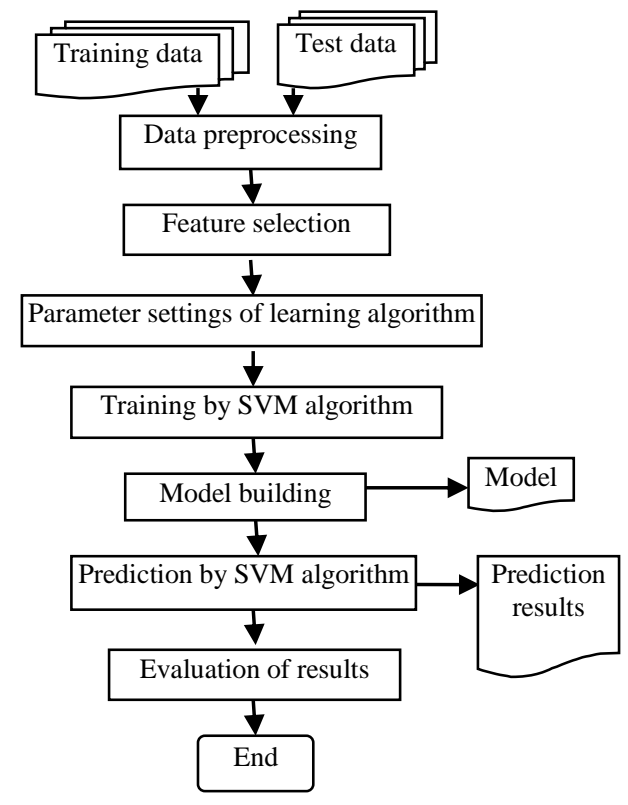

Fig. 1. Flow of data mining

The implementation steps of data mining will be given. We collect and input the values of evaluation metrics, including teaching workload, teaching achievement score, teaching effectiveness score, the scores given by students, experts and other teachers. According to these data, we establish the training set and test set. After the selection of feature, we call the SVM learning algorithm to execute the training, and obtain the training model. Finally, according to the given values of evaluation metrics and the established model, we implement the prediction of SVM algorithm. The prediction values and levels of the professional morality and ability of teachers will be given. There are two evaluation levels, including general level and good level. The experimental flow of data mining is shown as Fig. 1.

\section{RELATED PROMOTION STRATEGIES}

According to the analysis results of data mining, this paper gives some related strategies and suggestions to improve the professional morality and ability of teachers. From the practical views, we investigate and sum up the way for the improvement of quality of education. There are five aspects as follows.

Firstly, it is necessary to modify the current promotion system of teachers in some Chinese universities, and regard the teaching and scientific research as equal important work. The traditional promotion system for teachers only depends on the scientific research achievements of teachers, which is the important reason of ignoring the teaching. We should give the priority to the teachers with the outstanding teaching performance in the promotion of professional ranks and titles.

Secondly, we should formulate relevant rules and regulation for the evaluation mechanism, including the educational system, evaluation system and evaluation metrics, and provide a useful supplement for the improvement of the evaluation mechanism in the college and university. We need to improve the evaluation of professional morality of teachers. It is necessary to quantify the professional morality of teachers and develop a reasonable standard for the morality evaluation of teachers. In addition, we should further refine the evaluation criteria of teaching ability and teaching effectiveness, and improve the teaching evaluation for teachers.

Thirdly, according to the situation of teaching, we should strengthen the professional training for teachers, improve teaching level and comprehensive quality of teachers, and establish a reasonable education and training mechanism to adapt to the teaching reform. On the one hand, we should strengthen the professional morality training of teachers. On the other hand, we should strengthen the teaching ability training to the teachers.

Fourthly, we should make full use of the network platform and build a three-dimensional, teaching evaluation system. The evaluation scores are collected from students, experts and other teachers via network. At the same time, we should carry out various activities for the selection of teachers with the outstanding teaching. For the teachers with the excellent teaching performance and strong teaching ability, we should give a variety of incentives.

Fifthly, we should establish a perfect incentive strategy for teaching and attach importance to teaching. To strengthen the construction of morality and ability of teachers, we should also improve the income of teachers. It is important to improve the lecture fees and the basic income of teachers to better the living standard of teachers.

On the basis of the relevant strategies, we adopt experimental teaching to verify the results of the reform. According to the proposed strategy, we realize the teaching reform in some parts of departments and colleges as an experiment in practice. By the experiment, we verify the promotion of morality and ability of teachers and further test 
the effect of teaching reform. After the experiment in practice, we will gradually implement the teaching reform in the universities and realize the construction of morality and ability of teachers. According to the practical analysis of data mining, it obtains the theoretical strategies. And then it returns to practice in accordance with the theoretical strategies and further verify the results. It is an important example of the combination of theory and practice.

\section{CONCLUSION}

In this paper, it builds the evaluation metrics and model, and evaluates the professional morality and ability of teachers from the perspective of data mining. We adopt the SVM algorithm to realize the evaluation of professional morality and ability of teachers. It can predict the evaluation level of teachers based on SVM. In addition, according to the analysis of data mining, the paper gives the corresponding strategies to improve the professional morality and ability of teachers in order to realize the teaching reform. How to evaluate the professional morality of teachers will be the next research direction in the future.

\section{ACKNOWLEDGMENT}

This research is supported by the Tianjin Social Science Foundation of China (TJYY15-017).

\section{REFERENCES}

[1] M. S. Jiang, "Problems of the Construction of Teacher's Morality System in University and Route Choices," Journal of Hubei Correspondence University, vol. 29, no. 22, pp. 5-6, 2016. (In Chinese)

[2] K. Dong, "A Long-term Mechanism of University Teacher's Morality Construction," Journal of Anhui Science \& Technology University, vol. 30, no. 2, pp. 100-104, 2016. (In Chinese)

[3] J. Zhang, "Research on evaluation model of university teacher's research ability based on rough set and SVM technology". Chongqing, China, Chongqing university of technology, 2014. (In Chinese)

[4] T. Gao, P. Chen, "Evaluation model of research ability of teachers in universities based on rough set and group Eigenvalue," Science and technology management research, vol. 31, no. 21, pp. 131-133, 2011. (In Chinese)

[5] L. Li, J. Zhang, "Evaluation of university teacher's research ability based on rough set and association rules," Journal of Chongqing university of technology(natural science), vol. 28, no. 1, pp. 69-74, 2014. (In Chinese)

[6] Y. Zhang, X. Guan, H. Wang, et al. "Research on Teaching Ability Evaluation Model of University Teachers Based on Fuzzy Theory," Fifth International Conference on Computational and Information Sciences, pp. 1879-1881, 2013.

[7] Vapnik. The nature of statistical learning theory. Berlin:Springer, 2000.

[8] Chang C C, Lin C J, "LIBSVM: a library for support vector machines," http://www.csie.ntu.edu.tw/ cjlin / libsvm/. 